\title{
Internet Development, Spatial Spillover and Upgrading of China's Consumption Structure: A Spatial Econometrics Analysis Based on Data of 242 Cities during 2005-2016
}

\author{
Zhong Xiaoying ${ }^{1, *}$, Ke Kaili2, b \\ ${ }^{1}$ Nanfang College, Sun Yat-sen University, Guangzhou, Guangdong 510970, China \\ ${ }^{2}$ School of Management, Guangzhou University, Guangzhou, Guangdong 510006, China
}

\begin{abstract}
Based on the household survey data from 242 cities at and above the prefecture level during 2005-2016, this study evaluates changes in the upgrading of China's consumption structure, and investigates the overall and regional impacts of Internet development and spatial spillover on the upgrading of China's consumption structure using the spatial Durbin model (SDM) with time fixed effects. The results suggest that China's consumption structure remains basically stable in periodic changes, and there is a positive spatial correlation; China's Internet development exerts significantly promoting effects on the upgrading of residents' consumption structure, and there is a regional heterogeneity, namely, such effects in Eastern China and Central China are more remarkable than those in Western China; Internet development in neighboring cities has indirect effects on the upgrading of urban residents' consumption structure through spatial spillover effects, and there are regional differences in such effects. This study provides enlightenment for promotion of the upgrading of residents' consumption structure and the high-quality economic development in China.
\end{abstract}

\section{Introduction}

The upgrading of residents' consumption structure contributes significantly to the upgrading of industrial structure as well as economic growth and transformation. The contradiction accumulated as a result of the impact of the 2008 international financial crisis and the long-term extensive economic growth model poses a daunting challenge facing China's economic development, namely, the investment-driven and export-driven economy is unsustainable in the long run. Since 2019, the frequent international trade frictions, rising trade protectionism, and a genuine backlash against globalization have led to the tightening international trade situation that poses more grim and austere challenges facing China's foreign trade development. Therefore, the expansion of domestic demand remains an engine driving the long-term sustainable development of China's economy. Additionally, with the burgeoning Internet development in China, the implementation of "Internet +" strategy has significantly expedited the development of the Internet economy, resulting in remarkable changes in residents' consumption patterns and options. Against this background, it is of great theoretical and practical significance to investigate the evolution rules of the upgrading of China's residents' consumption structure and the impact of Internet development on the upgrading of China's consumption structure for the promotion of the long-term sustainable development of China's economy.
Scholars have conducted numerous studies on the relationship between Internet development and the upgrading of consumption structure. Based on Milton Friedman's permanent income hypothesis [1], Duesenberry's relative income hypothesis [2] and Keynes's absolute income hypothesis [3], scholars have investigated the upgrading of consumption structure. The upgrading of consumption structure generally means that a rise in people's income will lead to the transition from the demand for basic survival to the demand for enjoyment-oriented and development-oriented consumption, exhibiting the changes in the proportion of different types of consumption goods in people's consumption [4], and the reduced proportion of food expenditure in consumption expenditure (i.e., a decline in the Engel coefficient) [5]. The following aspects show the impact of Internet development on the upgrading of consumption structure:

(1) Internet development affects non-food expenditure. In view of the large proportion of food expenditure in urban and rural consumption, the proportion of non-food expenditure will increase and the residents' consumption structure will tend to follow the trend with the Internet development [6]. This is attributable to the reason that the increase in per-capita income and consumers' pursuit of individualization, quality and experience in the "Internet +" age will lead to a rise in non-food expenditure [7].

(2) Internet development affects enjoyment-oriented and development-oriented consumption. Internet development causes the 
transition in the consumption structure from survival-oriented consumption to enjoyment-oriented and development-oriented consumption with the rise in the income, and a decline in the Engel coefficient is the key indicator for the upgrading of consumption structure [8]. Internet development is conducive to increasing the proportion of family development and enjoyment-oriented consumption. Specifically, there is a remarkable rise in the proportion of family expenditure on culture, education and entertainment, which negatively affecting health care expenditure [9]. Internet development can promote development-oriented consumption and reduce the expenditure for survival-oriented consumption. However, Internet development exerts significantly negative effects on the expenditure for enjoyment-oriented consumption in cities, yet it exerts insignificantly positive effects on the expenditure for enjoyment-oriented consumption in rural areas [6].

(3) Internet development affects the upgrading of consumption structure, and there are urban-rural and population differences. Internet development can play a greater role in promoting the upgrading of urban consumption structure [6]. Internet development can noticeably promote the survival-oriented consumption of rural residents, yet it exerts marginal effects on the enjoyment-oriented consumption of rural residents [10]. Internet development contributes to the rise in the proportion of the expenditure for enjoyment-oriented and development-oriented consumption of rural residents to varying degrees, yet it causes a slight fall in the aforementioned proportion for urban residents, which may be due to the crowding-out effects of rising housing prices in cities and towns on enjoyment-oriented and development-oriented consumption [11].

According to the existing literature, the relationship between Internet development and the upgrading of consumption structure has been extensively explored, yet the spillover effects have been generally ignored. Scholars believe that Internet development has obvious externalities and spillover effects, such as knowledge spillover [12] and technology spillover [13], and such externalities positively stimulate the economic growth [1]. Salahuddin et al. [14] proved that Internet development could facilitate the economic growth based on the data from South Africa during 1991-2013. Liu and Chen [15] proved that Internet development could structurally strengthen the economic growth based on the spatial panel data model and the panel data from 31 provinces in China during 2007-2015. Clarke and Scott [16] and Bojnec et al. [17] found that Internet development contributed positively to international trade. Yang and Chu [18] found that Internet development could hinder the local import trade, yet it could advance the trade in neighboring regions. Pan and Xiao [19] found that Internet development could facilitate export trade through reducing the costs of information search, communication and production.
This exhibits that most studies primarily focus on Internet spillover effects on economy and trade, and Internet spillover effects on the upgrading of consumption structure are rarely reported.

Unlike previous studies, this study explores the impact of Internet development on the upgrading of China's residents' consumption structure from the perspective of spatial spillover. The marginal contribution of this study is mainly reflected in the following aspects: First, the impact of Internet development on the upgrading of China's consumption structure is explored using the spatial Durbin model (SDM) with time fixed effects and the data of 242 cities at and above the prefecture level during 2005-2016 from the perspective of spatial spillover. Existing studies on consumption structure generally ignore the spatial spillover effects of Internet development. This study systematically and comprehensively investigates the impact of Internet development from the perspective of spatial spillover effects. Second, the regional heterogeneity of Internet development for the upgrading of China's residents' consumption structure is examined. Third, the spatial econometric model is selected objectively using the Lagrange multiplier (LM) test for scientific modeling and estimation, thus avoiding the subjectivity in the selection of empirical model.

\section{Changes in the upgrading of China's residents' consumption structure}

Based on the data regarding the expenditure for consumption of residents in 242 cities in China during 2005-2016, this study shows that the upgrading of China's residents' consumption structure ldc presents the following characteristics:

1. $\quad l d c$ in China remains basically stable during the periodic changes (Fig. 1). During 2005-2016, $\quad l d c$ decreases from 0.417 to 0.393 in 2008 , increases to 0.439 in 2011 , then fluctuates to 0.385 in 2013, and finally rises to 0.417 in 2016, indicating that the upgrading of China's residents' consumption structure is characterized by fluctuations, and tends to rise over these years. During 2005-008, $\quad l d c$, which is subjected to the international financial crisis, drops to 0.393 , and China's residents' consumption structure is slowly upgraded, and even worsens. During 2009-2016,

ldc steadily increases, declines to 0.385 in 2013, and then begins to rise. During this period, China's residents' consumption structure shows a generally rising trend. The comparison reveals that China's residents' consumption structure shows a fluctuating and rising trend at the early stage and a declining trend at the subsequent stage, exhibiting a generally stable trend and an insignificant upward 
trend. The aforementioned analysis demonstrates that the upgrading of China's residents' consumption structure has periodic characteristics and remains basically stable, and the upgrading of the consumption structure should be expedited. Therefore, the promotion of the upgrading of China's residents' consumption structure and improvement of the quality of domestic demand remain crucial to drive the long-term sustainable development of China's economy.

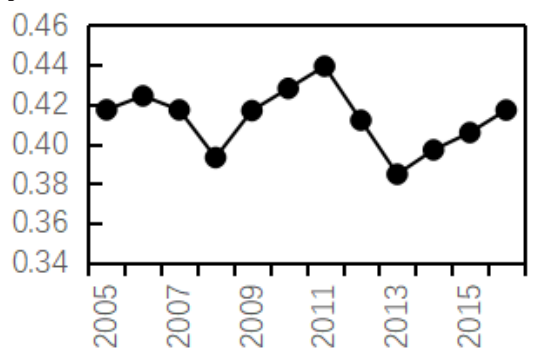

Fig. 1 Changes in $l d c$ in China during 2005-2016

2. Convergence of $\quad l d c$ in different regions in the process of differentiating changes (Fig. 2). With a view to further investigating the heterogeneity of the upgrading of consumption structure in different regions in China, we divided 242 cities into three major regions: Eastern China, Central China and

Western China. Fig. 2 shows the changes of $\quad l d c$ in different regions during 2005-2016. (1) This indicates that $\quad l d c$ in Eastern China, Central China and Western China is consistent with the overall trend during the investigation period, showing the basic trend of "rising, falling and then stabilizing". However, there are marked differences. From the perspective of absolute value, $\quad l d c$ in Eastern China is higher than that in Central China and Western China every year. During the investigation period, $\quad l d c$ rises from 0.442 to 0.450 in 2011, and then remains at around 0.400 . The consumption structure in Eastern China generally worsens, yet the level of consumption in Central China and Western China is relatively low, rising from 0.391 and 0.413 to 0.433 and 0.435 in 2011 , and then to 0.414 , respectively. This exhibits an obvious trend in the upgrading of consumption structure in Central China and Western China. The aforementioned analysis shows that there are marked differences in the upgrading of consumption structure among different regions in China, there is a declined trend in the high-quality consumption structure in Eastern China, and the upgrading of consumption structure in

(1) Eastern China includes Beijing, Tianjin, Liaoning, Hebei, Shanghai, Jiangsu, Zhejiang, Fujian, Shandong, Guangdong and Hainan, Central China includes Shanxi, Jilin, Heilongjiang, Anhui, Jiangxi, Henan, Hubei and Hunan, and Western China includes Inner Mongolia, Guangxi, Chongqing, Sichuan, Guizhou, Yunnan, Tibet, Shaanxi, Gansu, Qinghai, Ningxia and Xinjiang.
Central China and Western China is promising.

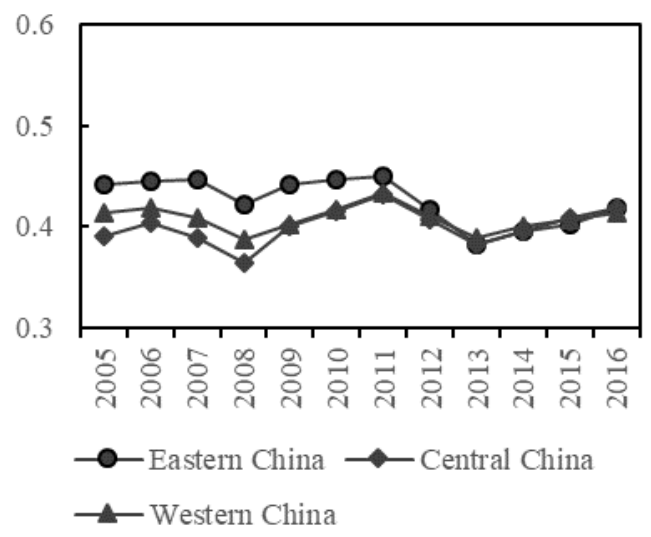

Fig.2 Changes of $l d c$ in various regions during 2005-2016

3. ldc in cities shows a strong positive spatial correlation. In this study, the scatter diagram of Moran for ldc in some years are plotted using the spatial weight matrix of geographical boundaries. The results suggest that the index of Moran is significantly positive and highly stable every year, and the index is basically maintained at 0.65 (Fig. 2). The index of $\quad l d c$ in China's cities is 0.661 in 2005 , rises to 0.742 in 2009 , remains at 0.672 in 2013, and becomes 0.700 in 2016 . This suggests that $\quad l d c$ in China's cities shows a strong positive spatial correlation in major years, and the basic spatial patterns of high-high and low-low agglomeration are maintained among cities. It is worth noting that the spatial correlation of $l d c$ in China's cities, subjected to the international financial crisis, is improved in 2009. During the investigation period, there is a strong positive spatial correlation in the consumption structure of urban residents in China, suggesting that the synergetic and linked strategies (e.g., the spatial linkage between urban clusters) should be implemented during the promotion of the upgrading of the consumption structure of urban residents in China. 

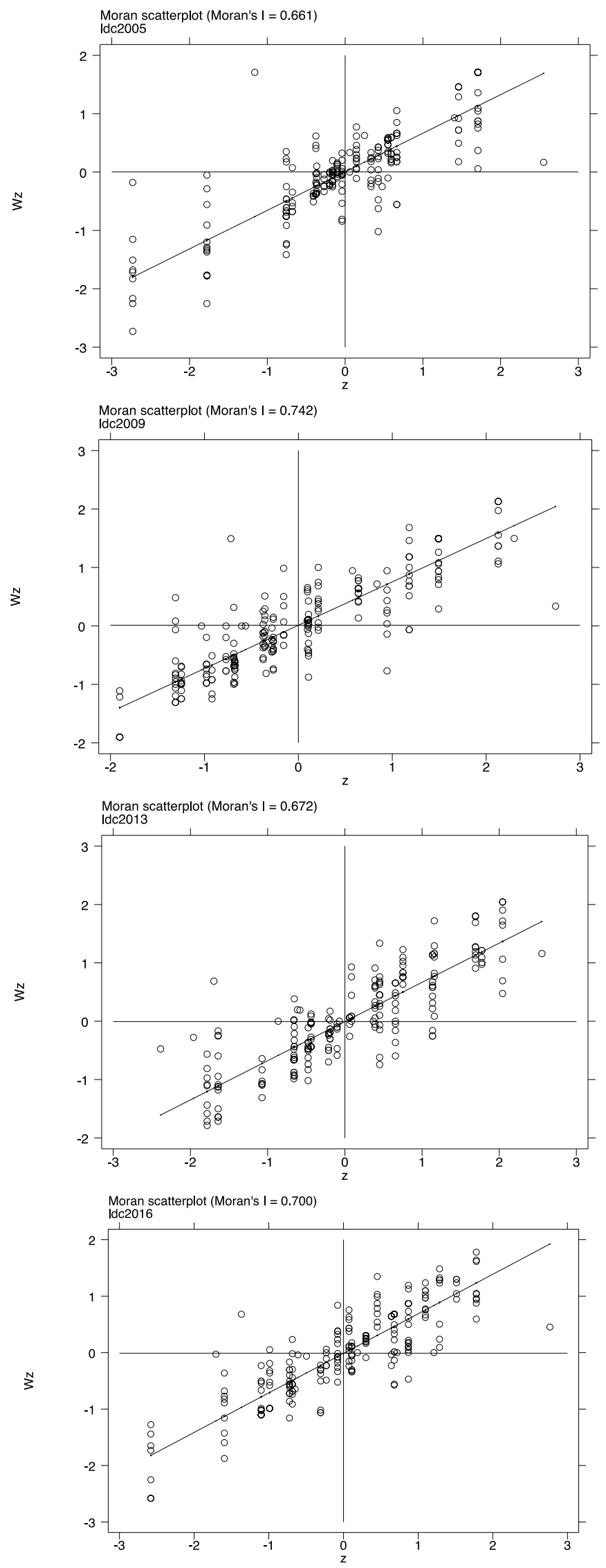

Fig. 3 Scatter diagram of $l d c$ for Moran in China's cities in some years 


\section{Econometric model}

\subsection{Model setting}

The aforementioned analysis reveals that there is a positive spatial correlation in China's urban consumption structure, and the consumption in neighboring cities significantly affects the cities. Therefore, it is necessary to establish a spatial econometric model including spatial correlation for analysis, so as to scientifically reveal the impact of the urban Internet development on the upgrading of residents' consumption structure. By reference to the generalized spatial panel model proposed by Baltagi et al. [20] and Lesage et al. [21], we take the upgrading of consumption structure of urban residents and the level of Internet development as the explained variable and explanatory variable, respectively. The SDM with control variables can be set as follows:

$l d c_{i t}=\rho W * l d c_{i t}+\beta_{1} \ln _{n} b u_{i t}+\beta_{2} W^{*} \ln e b u_{i t}+\gamma_{1} Z_{t}+\gamma_{2} W^{*} Z_{t}$

$+\alpha_{i}+\eta_{t} l_{N}+\varepsilon_{t}$

Where, $\quad l d c_{i t}$ indicates the $\mathrm{N}^{*} 1(\mathrm{~N}=1,2, \ldots, 242)$ vector for the upgrading of consumption structure of residents in prefecture-level

cities in $\quad t_{(} t_{=2005,2006, \ldots, 2016) \text {, and }}$ the vector is expressed using the proportion of the expenditure for urban residents' enjoyment-oriented and development-oriented consumption in total expenditure. $\quad \operatorname{lnebu}_{i t}$ indicates $\mathrm{N}^{*} 1$ vector for urban Internet development, $\quad Z_{t}$ indicates $\mathrm{N}^{*} \mathrm{~K}$ matrix of control variable, and $\quad W$ indicates $N^{*} \mathrm{~N}$ spatial weight matrix with non-negative and exogenous main diagonal elements being 0 . Here is the adjacent weight matrix of urban boundary, and if the adjacent element takes 1 , otherwise it takes 0 .
$\tau$
$\rho, \quad \beta_{1}$ and
$\beta_{2}$ indicate the coefficients of the first-phase lag of the explained variable, the spatial lag term, the core explanatory variable and the lag term, respectively. $\quad \alpha_{i}$ and

$\eta_{t}$ indicate the urban and time fixed effects, $l_{N}$ indicates the column vector with $\mathrm{N}^{*} 1$ elements being 1 , and $\quad \varepsilon_{t}$ indicates the random disturbance term. The model (1), which is a SDM, considers the spatial lag terms of the dependent and independent variables, so as to reflect the spatial spillover effects between the upgrading of urban residents' consumption structure and the spatial spillover effects of E-commerce development. If

$$
\beta_{2}=0 \text {, it shows that there is no spatial }
$$
spillover effect in E-commerce development.

\subsection{Model selection}

In the aforementioned models, the use of different sample data may cause the models to degenerate into simple Spatial autoregressive (SAR) model or spatial error model (SEM). ${ }^{(1)}$ The SAR model means that only the dependent variable has spatial lag effects, while the SEM means that only the error term has spatial lag effects. Therefore, we take the general SDM as the starting point, and analyze whether the SDM will degenerate into SAR model and SEM using the LM test. Compared with the traditional econometric model, the spatial econometric model incorporates spatial related factors and has endogenous issues, and the ordinary least squares (OLS) estimation is biased and inconsistent. Therefore, based on the study conducted by LeSage [21], we conduct the estimation using the maximum likelihood method, and select models using the LM test.

It is noteworthy that the incorporation of the spatial weight matrix in the spatial econometric model leads to marked differences between the spatial weight matrix and the traditional econometric model. If a coefficient is obtained by direct estimation based on the spatial econometric model, it may lead to biased conclusions, because the coefficient does not represent the marginal effects of explanatory variables. Therefore, the basic principle of spatial econometric model should be followed, and the marginal effects should be obtained from the following matrix:

$$
\begin{aligned}
& {\left[\begin{array}{lll}
\frac{\partial E(\text { consum })}{\partial e b u s 1} & \cdots & \frac{\partial E(\text { consum })}{\partial e b u s N}
\end{array}\right]} \\
& =\left(\begin{array}{ccc}
\frac{\partial E(\text { consum })}{\partial e b u s 1} & \cdots & \frac{\partial E(\text { consum })}{\partial e b u s N} \\
\vdots & \ddots & \vdots \\
\frac{\partial E(\text { consum })}{\partial e b u s 1} & \cdots & \frac{\partial E(\text { consum })}{\partial e b u s N}
\end{array}\right) \\
& =(1-\rho W)^{-1}\left(\beta_{1} E_{N}+\beta_{2} W\right)
\end{aligned}
$$

Where, $\quad E_{N}$ is $\mathrm{N}^{*} \mathrm{~N}$ identity matrix. In formula (2), the mean of main diagonal elements and the sum of non-diagonal elements of the matrix represent the direct effect and the indirect effect, respectively [21]. The mean of main diagonal elements represents the direct effect of urban Internet development on the upgrading of consumption structure, including feedback effect, namely, the impact of urban Internet development on the upgrading of residents' consumption structure will be transmitted to other cities, and other cities will provide feedbacks on the urban Internet development, and transmit them to this city, thus affecting the

\footnotetext{
(1) The two common spatial econometric models (i.e., SAR model and SEM) are primarily considered in this study.
} 
upgrading of consumption structure of this city and other cities. The feedback effect is measured by the mean of the sum of rows (columns) of non-diagonal elements. If $\rho=\beta_{2}=0$, there is no indirect effect. If $\rho=0$ and $\beta_{2} \neq 0$, there are local indirect effects. This demonstrates that the upgrading of urban consumption structure in China only affects its neighboring cities. If $\quad \rho \neq 0$ and $\beta_{2}=0$, there are global indirect effects, suggesting that the upgrading of urban consumption structure in China affects all other cities. If

$$
\rho \neq 0 \text { and } \beta_{2} \neq 0 \text {, there are local and }
$$
global indirect effects. Additionally, since our investigation period is from 2005 to 2016, the aforementioned effects are short-term effects.

\subsection{Variable selection and data sources}

1. Urban consumption structure $l d c_{i t}$. According to the classification criteria of National Bureau of Statistics of China, the total consumption expenditure of residents in China includes eight sub-items, namely, food, clothing, housing, daily necessities and services, transportation and communication, education, culture and entertainment, and medical care and other supplies and services. In terms of index processing, some scholars use Engel coefficient (i.e., the proportion of food consumption expenditure) as the index for measurement of residents' consumption structure. A decline in this proportion indicates the upgrading of consumption structure. In multiple studies, an increase in the proportions of some or all of the last five items in the aforementioned eight sub-items is viewed as the upgrading of consumption structure $[22,6]$. The comparison of the urban household survey data released by authorities at different levels shows that only the overall consumption expenditure data and the consumption expenditure data for the first three items are provided regarding the household survey data in many cities. Therefore, this study measures the consumption structure of urban residents using

the proportion $\quad l d c$ of expenditure for enjoyment-oriented and development-oriented consumption. The enjoyment-oriented and development-oriented consumption includes the last five items in the aforementioned eight sub-items, and the other three items are regarded as the basic living consumption. Each urban index is obtained by weighted average based on the corresponding values of cities and towns and rural areas, and the weight coefficients are the proportions of resident population in cities and towns and rural resident population, respectively. In 2012, China initiated the integrated reform for investigation of urban and rural households. Subsequently, cities successively released the latest data. Based on the latest and previous data, we smoothed the data without changing the changing trend of the data prior to adjustment. For cities with missing data, we supplement the missing data based on the changing trend of the corresponding data in the provinces where the cities are located.

2. Internet development $l n e b u_{i t}$. It is expressed using the number of fixed-line telephone, mobile telephone and broadband users, and is logarithmic.

\section{Control variables $Z$. (1) Residents'}

income growth ig. It is measured by the ratio of per capita disposable income between the current year and the previous year, the per capita disposable income of urban residents is the weighted sum of the per capita disposable income of residents in cities and towns and rural residents, and the weight coefficient is the proportion of resident population in cities and towns and rural resident population. (2) Urban-rural

income gap gap. According to Wang et al. [23], it is expressed using the ratio of per capita income between residents in cities and towns and rural residents. (3) Financial expenditure intensity

$f i n$. It is expressed using the ratio of general budget expenditure of urban government to GDP. The fiscal expenditure of local government (e.g., social security expenditure) can reduce urban residents' savings and promote their consumption. Therefore, the fiscal expenditure may affect the upgrading of residents' consumption structure. (4) Urbanization

level urban. It is measured by the proportion of non-agricultural population in registered population. It is generally believed that the improvement of urbanization level will stimulate the demand for urban public services, expedite the growth of service industry, and expand the employment opportunities, and the income of urban residents can be increased through economies of scale and external economies, so as to improve the consumption demand and structure [23]. (5) Financial market efficiency $f \epsilon$. According to the common practice, it is expressed using the ratio of the sum of savings deposits and loans in financial institutions to GDP. Gourinchas and Parker believe that a family can make financial decisions through allocation of intertemporal resources (e.g., savings, investment, and debit and credit), so as to increase wealth and promote consumption. [24] Therefore, financial market efficiency will affect residents' consumption, and then act on the upgrading of consumption

structure. (6) Industrial structure is. According to $\mathrm{Ma}$, it is expressed using the ratio of secondary and tertiary industries to GDP [25]. The original data involved in the aforementioned variables are obtained from China Yearbook of Household Survey, China City Statistical Yearbook, China Statistical Yearbook for Regional Economy, Population Statistics for China's Counties and Cities, provincial population 
census data, provincial household survey yearbooks, provincial statistical yearbooks, prefecture-level statistical yearbooks, prefecture-level statistical bulletin on national economic and social development, and websites of prefecture-level bureaus of statistics.

\section{Analysis of empirical results}

\subsection{Overall analysis of results}

Prior to the analysis of the relationship between the E-commerce development as well as spatial spillover and the upgrading of China's residents' consumption structure, we investigate which model can more effectively fit the sample data. Table 1 shows the estimated results of different spatial econometric models. First, we estimate the SDM corresponding to formula (1), and obtain the fixed and random effect models. Then, we conduct the Hausman test. According to the time-fixed, space-fixed and double-fixed effects, the corresponding Hausman test results are 432.1, 79.4 and 100.9, respectively. The original hypothesis is rejected, indicating that the fixed effect model should be adopted. The comparison of the three values exhibits that the time-fixed effect corresponds to the largest Hausman test statistics. Therefore, the SDM with time-fixed effects should be adopted for estimation. To further analyze whether SDM will degenerate into SAR model and SEM, we carry out the corresponding LM tests, respectively. This shows that the $\mathrm{P}$ values in LM tests for SAR model and SEM are 1, and the original hypothesis is not rejected, indicating that SDM with time-fixed effects is superior to SAR model with time-fixed effects and SEM with time-fixed effects. In summary, this study uses SDM with time-fixed effects for estimation, on which the following analysis is primarily based.

According to the column (1), the spatial lag term $w * l d c$

for

the

proportions

of enjoyment-oriented and development-oriented consumption is significantly positive, indicating that there are significantly positive spatial spillover effects in the China's residents' consumption structure, namely, an increase in the expenditure for enjoyment-oriented and development-oriented consumption will drive the upgrading of consumption structure in the city. The coefficient lnebu of Internet development is positive, and has passed the test with a level of significance of $1 \%$, demonstrating that the Internet development contributes significantly to promoting the upgrading of China's consumption structure. An increase in per-capita income and consumers' pursuit of individualization, quality and experience in the "Internet + " age will lead to a rise in non-food expenditure [7], thereby facilitating the upgrading of China's consumption structure. The coefficient $\quad w *$ lnebu of Internet spatial lag term is significantly positive, demonstrating that an elevation in the level of Internet development in neighboring cities will cause spatial spillover effects to the cities, thus promoting the upgrading of residents' consumption structure in the cities. It is noteworthy that the core variable coefficient in SDM does not directly represent its impact on the dependent variable. In view of this, we calculate its direct, indirect and total effects in accordance with formula (2). This exhibits that each

effect coefficient of lnebu is significantly positive, signaling that the urban Internet development in China will remarkably advance the upgrading of residents' consumption structure. This may be attributable to the reason that the surging development of information and communication technologies (e.g., the Internet) can increase the number of transactions per unit time and reduce transaction costs [26], produce market-wide effects in cities and exert influences (e.g., knowledge and technology spillovers) on the Internet development in other cities, and finally affect the upgrading of consumption structure in other cities [27]. Additionally, the indirect effect coefficient (0.008) is higher than the direct effect coefficient, exhibiting that the impact of Internet development in neighboring cities on the upgrading of local urban consumption structure cannot be ignored. This proves the rationality for selection of spatial econometric model. Compared with the traditional econometric model, the SDM adopted in this study can fully reveal the relationship between the Internet development and the upgrading of China's residents' consumption structure.

In terms of control variables, the direct, indirect and total effects of urban income growth ig are positive, but the insignificantly indirect effect indicate that local residents' income growth will obviously promote the upgrading of consumption structure, which is consistent with the theory on traditional consumption structure. However, the income growth in neighboring cities insignificantly affects the upgrading of local urban consumption structure, suggesting that the income growth in neighboring cities will not noticeably affect the upgrading of local urban consumption structure. The

effects of other variables (e.g., gap and

is ) are basically significantly positive, demonstrating that the widening urban-rural income gap and the upgrading of industrial structure can remarkably promote the upgrading of urban residents' consumption structure in China. This may be related to the slow income growth of rural residents in China. As urbanization rapidly expands, there is a surge in urban residents' income and a weak income growth in rural residents, resulting in the widening income gap between urban and rural residents. The rapid income growth of urban residents is conducive to the overall upgrading of China's residents' consumption structure. However, the slow income growth of rural 
residents and their large food expenditure hinder the upgrading of China's residents' consumption structure to a certain extent. The impacts of urban, $f$ in and $f \mathrm{e}$ are negative, and the values are relatively small, suggesting that insufficient efforts are made to expedite urbanization, and improve fiscal expenditure and financial efficiency.

Table 1 Estimated results and impact decomposition based on spatial econometric model

\begin{tabular}{|c|c|c|c|c|c|c|c|c|c|}
\hline Variables & & & & SDM & & & & SAR & SEM \\
\hline$w * l d c$ & $\begin{array}{c}\text { Time-fixe } \\
\mathrm{d} \\
0.757 * * * \\
(0.026)\end{array}$ & $\begin{array}{l}\text { Direct } \\
\text { effects }\end{array}$ & $\begin{array}{l}\text { Indirect } \\
\text { effects }\end{array}$ & $\begin{array}{c}\text { Total } \\
\text { effects }\end{array}$ & $\begin{array}{c}\text { Space-fixe } \\
\mathrm{d} \\
0.811^{* * *} \\
(0.010)\end{array}$ & $\begin{array}{c}\text { Double-fix } \\
\text { ed } \\
0.745^{* * *} \\
(0.012)\end{array}$ & $\begin{array}{c}\text { Random } \\
0.784 * * * \\
(0.010)\end{array}$ & $\begin{array}{c}\text { Time-fixed } \\
0.847 * * * \\
(0.010)\end{array}$ & $\begin{array}{c}\text { Time-fixed } \\
0.802 * * * \\
(0.011)\end{array}$ \\
\hline lnebu & $\begin{array}{c}0.004 * * * \\
(0.001)\end{array}$ & $\begin{array}{c}0.005 * * \\
* \\
(0.001 \\
)\end{array}$ & $\begin{array}{c}0.008 * \\
(0.004)\end{array}$ & $\begin{array}{l}0.013 * * \\
(0.005)\end{array}$ & $\begin{array}{c}-0.001 \\
(0.001)\end{array}$ & $\begin{array}{c}0.001(0.00 \\
1)\end{array}$ & $\begin{array}{c}0.002 * \\
(0.001)\end{array}$ & $\begin{array}{c}0.004 * * * \\
(0.001)\end{array}$ & $\begin{array}{c}0.003 * * * \\
(0.001)\end{array}$ \\
\hline$i g$ & $\begin{array}{c}0.021 * * * \\
(0.001)\end{array}$ & $\begin{array}{c}0.021 * * \\
(0.002 \\
)\end{array}$ & $\begin{array}{c}0.003 \\
(0.004)\end{array}$ & $\begin{array}{c}0.024 * * * \\
(0.004)\end{array}$ & $\begin{array}{c}0.009 * * * \\
(0.003)\end{array}$ & $\begin{array}{c}0.014 * * * \\
(0.003)\end{array}$ & $\begin{array}{c}0.018^{* * * *} \\
(0.003)\end{array}$ & $\begin{array}{c}0.005 * * * \\
(0.001)\end{array}$ & $\begin{array}{c}0.019 * * * \\
(0.002)\end{array}$ \\
\hline gap & $\begin{array}{l}0.012 * \\
(0.007)\end{array}$ & $\begin{array}{l}0.011 \\
(0.007 \\
)\end{array}$ & $\begin{array}{c}-0.008(0.01 \\
8)\end{array}$ & $\begin{array}{c}0.003(0.02 \\
1)\end{array}$ & $\begin{array}{l}0.013 * * \\
(0.006)\end{array}$ & $\begin{array}{l}0.014 * * \\
(0.006)\end{array}$ & $\begin{array}{c}0.037 * * * \\
(0.006)\end{array}$ & $\begin{array}{c}0.002 \\
(0.005)\end{array}$ & $\begin{array}{c}-0.007(0.00 \\
7)\end{array}$ \\
\hline fin & $\begin{array}{l}-0.005^{*} \\
(0.002)\end{array}$ & $\begin{array}{c}-0.013 * * \\
* \\
(0.003 \\
)\end{array}$ & $\begin{array}{c}-0.096 * * * \\
(0.018)\end{array}$ & $\begin{array}{c}-0.109 * * * \\
(0.021)\end{array}$ & $\begin{array}{c}0.000 \\
(0.002)\end{array}$ & $\begin{array}{c}-0.000(0.00 \\
2)\end{array}$ & $\begin{array}{c}0.000(0.00 \\
3)\end{array}$ & $\begin{array}{c}-0.002(0.00 \\
3)\end{array}$ & $\begin{array}{c}0.001(0.003 \\
)\end{array}$ \\
\hline urban & $\begin{array}{c}-0.000 * * \\
(0.000)\end{array}$ & $\begin{array}{c}-0.000 * * \\
* \\
(0.000 \\
)\end{array}$ & $\begin{array}{c}0.000 \\
(0.000)\end{array}$ & $\begin{array}{c}-0.000(0.00 \\
0)\end{array}$ & $\begin{array}{c}0.000(0.00 \\
0)\end{array}$ & $\begin{array}{l}-000 * * \\
(0.000)\end{array}$ & $\begin{array}{c}0.000 \\
(0.000)\end{array}$ & $\begin{array}{c}-0.000 * * \\
(0.000)\end{array}$ & $\begin{array}{l}-0.000 * \\
(0.000)\end{array}$ \\
\hline$f e$ & $\begin{array}{c}-0.001 * * * \\
(0.000)\end{array}$ & $\begin{array}{c}-0.002 * * \\
(0.001 \\
)\end{array}$ & $\begin{array}{c}-0.006 \\
(0.004)\end{array}$ & $\begin{array}{l}-0.007 * \\
(0.004)\end{array}$ & $\begin{array}{c}-0.001 * * \\
(0.000)\end{array}$ & $\begin{array}{c}-0.001 * * \\
(0.000)\end{array}$ & $\begin{array}{c}-0.001 * * \\
(0.000)\end{array}$ & $\begin{array}{c}-0.001 * * \\
(0.000)\end{array}$ & $\begin{array}{c}-0.001 * * \\
(0.000)\end{array}$ \\
\hline is & $\begin{array}{l}0.023 * * \\
(0.008)\end{array}$ & $\begin{array}{c}0.036^{* *} \\
* \\
(0.008 \\
)\end{array}$ & $\begin{array}{c}0.159 * * * \\
(0.039)\end{array}$ & $\begin{array}{c}0.196^{* * * *} \\
(0.043)\end{array}$ & $\begin{array}{c}-0.015 \\
(0.018)\end{array}$ & $\begin{array}{c}-0.023(0.01 \\
8)\end{array}$ & $\begin{array}{c}0.073 * * * \\
(0.014)\end{array}$ & $\begin{array}{l}0.025 * * \\
(0.007)\end{array}$ & $\begin{array}{l}0.019 * * \\
(0.008)\end{array}$ \\
\hline$w * \ln e b u$ & $\begin{array}{l}-0.011 * \\
(0.006)\end{array}$ & & & & $\begin{array}{c}-0.006 * * \\
(0.002)\end{array}$ & $\begin{array}{c}-0.001 \\
(0.002)\end{array}$ & $\begin{array}{c}-0.009 * * * \\
(0.002)\end{array}$ & & \\
\hline$w * i g$ & $\begin{array}{l}-0.011 * \\
(0.006)\end{array}$ & & & & $\begin{array}{c}-0.003 \\
(0.006)\end{array}$ & $\begin{array}{c}-0.006(0.00 \\
7)\end{array}$ & $\begin{array}{c}-0.028 * * * \\
(0.007)\end{array}$ & & \\
\hline$w^{*} g a p$ & $\begin{array}{c}-0.015 * * * \\
(0002)\end{array}$ & & & & $\begin{array}{l}-0.005^{*} \\
(0.003)\end{array}$ & $\begin{array}{c}-0.003 \\
(0.003)\end{array}$ & $\begin{array}{c}-0.015 * * * \\
(0.003)\end{array}$ & & \\
\hline$w * f i n$ & $\begin{array}{c}-0.021 * * * \\
(0.004)\end{array}$ & & & & $\begin{array}{l}-0.005 \\
(0.003)\end{array}$ & $\begin{array}{l}-0.007 * \\
(0.003)\end{array}$ & $\begin{array}{c}-0.009 * * \\
(0.004)\end{array}$ & & \\
\hline$w^{*} u r b a n$ & $\begin{array}{l}0.001 * * \\
(0.000)\end{array}$ & & & & $\begin{array}{c}0.000 \\
(0.000)\end{array}$ & $\begin{array}{l}0.000 * \\
(0000)\end{array}$ & $\begin{array}{c}0.001 * * * \\
(0.000)\end{array}$ & & \\
\hline$w^{*} f e$ & $\begin{array}{l}-0.001 \\
(0.001)\end{array}$ & & & & $\begin{array}{c}0.000(0.00 \\
1)\end{array}$ & $\begin{array}{c}0.000(0.00 \\
1)\end{array}$ & $\begin{array}{c}0.000(0.00 \\
1)\end{array}$ & & \\
\hline$w^{*} i s$ & $\begin{array}{l}0.025 * * \\
(0.011)\end{array}$ & & & & $\begin{array}{c}0.006 \\
(0.027)\end{array}$ & $\begin{array}{c}0.023(0.02 \\
8)\end{array}$ & $\begin{array}{c}-0.193 * * * \\
(0.017)\end{array}$ & & \\
\hline $\begin{array}{c}\text { Hausman } \\
\text { test }\end{array}$ & 432.1 & & & & 79.4 & 100.9 & & & \\
\hline LM test & & & & & & & & 1.000 & 1.000 \\
\hline $\begin{array}{l}\text { Likeliho } \\
\text { od }\end{array}$ & 7860 & 7860 & 7860 & 7860 & 7762 & 6948 & 7281 & 4002 & 4003 \\
\hline $\mathrm{R} 2$ & 0.05 & 0.05 & 0.05 & 0.05 & 0.01 & 0.03 & 0.01 & 0.02 & 0.01 \\
\hline $\begin{array}{l}\text { Observe } \\
\text { d Value }\end{array}$ & 2904 & 2904 & 2904 & 2904 & 2904 & 2904 & 2904 & 2904 & 2904 \\
\hline
\end{tabular}

Note: Hausman test shows that the fixed effect of SDM is a random effect, statistic is reported, LM tests correspond to the time fixed effect models of SDM, SAR model, and SEM, and P value is reported. The standard deviation is in coefficient brackets, and *,** and *** are at the levels of significance of $10 \%, 5 \%$ and $1 \%$, respectively. The same below.

\subsection{Analysis of regional results}

To further investigate whether there is regional heterogeneity in the impact of China's Internet development on the upgrading of residents' consumption structure, we divide the study samples into Eastern China, Central China and Western China, and conduct the re-estimations. Table 3 shows the results. This reveals that the direct effect of lnebu in Eastern China is significantly positive, and the indirect effect is significantly negative, suggesting that the Internet development in Eastern China can obviously promote the upgrading of residents' consumption structure. However, the 
Internet development in neighboring cities can exert remarkably negative effects on the upgrading of urban consumption structure in Eastern China, which may be due to the reason that the burgeoning Internet development in neighboring cities helps local urban residents to focus on enjoyment-oriented and development-oriented consumption, resulting in a transition from consumption in local cities to consumption in neighboring cities. The direct effect of Internet development in Central China is significantly positive, which is consistent with the overall result. This demonstrates that the impact of Internet development in neighboring cities Central China is slightly different from that in Eastern China, and the Internet development in neighboring cities can contribute significantly to the upgrading of residents' consumption structure. The impact of Internet development in Western China is not remarkable, signaling that Internet development in Western China does not directly or indirectly facilitate the upgrading of consumption structure. The aforementioned results may be attributable to the reason that compared with Western China, Eastern
China and Central China with a relatively high level of economic development enjoy a higher level of Internet development and a better infrastructure, expediting the Internet development, producing spatial spillover effects (e.g., technology and knowledge spillovers), and thus affecting the upgrading of residents' consumption structure in other regions. However, Western China has not yet played a stimulating role in the upgrading of residents' consumption structure because of the relatively backward soft and hard infrastructure (e.g., the Internet) and the relatively low agglomeration level. Liu and Zhang indicate that the Internet development drives the upgrading of China's rural consumption structure, and has a stronger impact on Eastern China than Western China and Central China [28]. Additionally, the impact of control variables is basically consistent with the overall impact. Briefly, China's Internet development and spatial spillover effects have different impacts on the upgrading of residents' consumption structure in different regions, and such impacts in Eastern China and Central China are stronger than those in Western China.

Table 2 Regional estimated results and decomposition

\begin{tabular}{|c|c|c|c|c|c|c|c|c|c|}
\hline \multirow[t]{2}{*}{ Variables } & \multicolumn{3}{|c|}{ Eastern China } & \multicolumn{3}{|c|}{ Central China } & \multicolumn{3}{|c|}{ Western China } \\
\hline & $\begin{array}{l}\text { Direct } \\
\text { effects }\end{array}$ & $\begin{array}{l}\text { Indirect } \\
\text { effects }\end{array}$ & $\begin{array}{c}\text { Total } \\
\text { effects }\end{array}$ & $\begin{array}{l}\text { Direct } \\
\text { effects }\end{array}$ & $\begin{array}{l}\text { Indirect } \\
\text { effects }\end{array}$ & $\begin{array}{l}\text { Total } \\
\text { effects }\end{array}$ & $\begin{array}{l}\text { Direct } \\
\text { effects }\end{array}$ & $\begin{array}{l}\text { Indirect } \\
\text { effects }\end{array}$ & $\begin{array}{c}\text { Total } \\
\text { effects }\end{array}$ \\
\hline lnebu & $\begin{array}{r}0.002 * * * \\
(0.001)\end{array}$ & $\begin{array}{r}-0.011 * * \\
(0.005)\end{array}$ & $\begin{array}{c}-0.009 \\
(0.006)\end{array}$ & $\begin{array}{c}0.007 * * * \\
(0.002)\end{array}$ & $\begin{array}{c}0.041 * * * \\
(0.011)\end{array}$ & $\begin{array}{c}0.048 * * * \\
(0.013)\end{array}$ & $\begin{array}{c}0.001 \\
(0.002)\end{array}$ & $\begin{array}{c}-0.008(0.01 \\
0)\end{array}$ & $\begin{array}{c}-0.007(0.01 \\
2)\end{array}$ \\
\hline$i g$ & $\begin{array}{r}0.017 * * * \\
(0.003)\end{array}$ & $\begin{array}{l}-0.002 \\
(0.006)\end{array}$ & $\begin{array}{l}0.015 * * \\
(0.006)\end{array}$ & $\begin{array}{r}0.070 * * * \\
(0.006)\end{array}$ & $\begin{array}{c}-0.059 * * * \\
(0.013)\end{array}$ & $\begin{array}{c}0.010 \\
(0.014)\end{array}$ & $\begin{array}{c}0.002(0.002 \\
)\end{array}$ & $\begin{array}{c}0.017 * * * \\
(0.004)\end{array}$ & $\begin{array}{c}0.019 * * * \\
(0.005)\end{array}$ \\
\hline gap & $\begin{array}{l}-0.202 * * \\
*(0.021)\end{array}$ & $\begin{array}{c}0.157 * * \\
(0.049)\end{array}$ & $\begin{array}{c}-0.045 \\
(0.052)\end{array}$ & $\begin{array}{c}-0.032 * * * \\
(0.009)\end{array}$ & $\begin{array}{l}0.087 * * \\
(0.032)\end{array}$ & $\begin{array}{c}0.055 \\
(0.035)\end{array}$ & $\begin{array}{c}-0.013(0.01 \\
2)\end{array}$ & $\begin{array}{c}0.029(0.019 \\
)\end{array}$ & $\begin{array}{c}0.016(0.017 \\
)\end{array}$ \\
\hline fin & $\begin{array}{l}-0.004 \\
(0.003)\end{array}$ & $\begin{array}{r}-0.036^{* *} \\
(0.012)\end{array}$ & $\begin{array}{c}-0.040 * * \\
(0.015)\end{array}$ & $\begin{array}{c}-0.028 * * \\
(0.013)\end{array}$ & $\begin{array}{c}-0.087 \\
(0.081)\end{array}$ & $\begin{array}{c}-0.115(0.09 \\
1)\end{array}$ & $\begin{array}{c}-0.003(0.00 \\
7)\end{array}$ & $\begin{array}{c}-0.003(0.03 \\
8)\end{array}$ & $\begin{array}{c}-0.006(0.04 \\
3)\end{array}$ \\
\hline urban & $\begin{array}{r}-0.000 * * \\
(0.000)\end{array}$ & $\begin{array}{c}0.000 \\
(0.000)\end{array}$ & $\begin{array}{c}-0.000(0.00 \\
0)\end{array}$ & $\begin{array}{c}-0.000 * * * \\
(0.000)\end{array}$ & $\begin{array}{c}-0.003 * * * \\
(0.001)\end{array}$ & $\begin{array}{c}-0.004 * * * \\
(0.001)\end{array}$ & $\begin{array}{c}-0.000 \\
(0.000)\end{array}$ & $\begin{array}{c}0.001(0.001 \\
)\end{array}$ & $\begin{array}{c}0.001(0.000 \\
)\end{array}$ \\
\hline$f e$ & $\begin{array}{r}-0.001 * * \\
(0.000)\end{array}$ & $\begin{array}{l}-0.002 \\
(0.003)\end{array}$ & $\begin{array}{c}-0.003(0.00 \\
3)\end{array}$ & $\begin{array}{c}0.004(0.00 \\
4)\end{array}$ & $\begin{array}{c}0.011(0.02 \\
7)\end{array}$ & $\begin{array}{c}0.015(0.030 \\
)\end{array}$ & $\begin{array}{c}0.005^{*} \\
(0.003)\end{array}$ & $\begin{array}{c}0.020 \\
(0.014)\end{array}$ & $\begin{array}{c}0.025(0.017 \\
)\end{array}$ \\
\hline is & $\begin{array}{r}0.064 * * * \\
(0.013)\end{array}$ & $\begin{array}{l}0.157 * * \\
(0.071)\end{array}$ & $\begin{array}{c}0.220 * * \\
(0.079)\end{array}$ & $\begin{array}{l}0.042 * * \\
(0.016)\end{array}$ & $\begin{array}{c}0.364 * * * \\
(0.083)\end{array}$ & $\begin{array}{c}0.406 * * * \\
(0.091)\end{array}$ & $\begin{array}{c}-0.011 \\
(0.024)\end{array}$ & $\begin{array}{l}-0.21 * * \\
(0.103)\end{array}$ & $\begin{array}{c}-0.261 * * \\
(0.116)\end{array}$ \\
\hline $\begin{array}{c}\text { Likelihoo } \\
\text { d }\end{array}$ & 3243 & 3243 & 3243 & 2386 & 2386 & 2386 & 2311 & 2311 & 2311 \\
\hline $\mathrm{R} 2$ & 0.01 & 0.01 & 0.01 & 0.06 & 0.06 & 0.06 & 0.01 & 0.01 & 0.01 \\
\hline $\begin{array}{l}\text { Observed } \\
\text { Value }\end{array}$ & 1152 & 1152 & 1152 & 996 & 996 & 996 & 756 & 756 & 756 \\
\hline
\end{tabular}

\section{Study conclusions and policy implications}

Based on the household survey data from 242 cities at and above the prefecture level during 2005-2016, this study evaluates changes in the upgrading of China's consumption structure, and investigates the overall and regional impacts of Internet development and spatial spillover on the upgrading of China's consumption structure using the spatial Durbin model (SDM) with time fixed effects. The results suggest that China's consumption structure remains basically stable in periodic changes, and there is a positive spatial correlation. China's Internet development exerts significantly promoting effects on the upgrading of residents' consumption structure, and there is a regional heterogeneity, namely, such effects in Eastern China and Central China are more remarkable than those in Western China. Internet development in neighboring cities has indirect effects on the upgrading of urban residents' consumption structure through spatial spillover effects, and there are regional differences in such effects.

This study provides enlightenment for promotion of the upgrading of China's consumption structure. First, China's residents' consumption structure shows 
a marked positive spatial correlation, indicating that the local residents' consumption structure is subjected to the consumption structure in neighboring cities. The policy implication lies in strengthening the linkage mechanism formulated by policies for inter-city consumption, synergistically stimulating the enjoyment-oriented and development-oriented consumption of urban residents, and promoting high-quality consumption in China. Second, Internet development contributes significantly to the upgrading of China's residents' consumption structure, exhibiting that the development of new types of business and new business models (e.g., E-commerce) is conducive to upgrading the consumption structure of China's residents. With the swift development of information and communication technologies (e.g., the Internet) and the complicated and volatile international situation, China is facing uncertainties in its high-quality economic development. Specifically, China's foreign trade is particularly subjected to the international situation. Against this background, it remains increasingly crucial to expand the domestic demand (e.g., the consumer demand) and upgrade residents' consumption structure. Therefore, with the "Internet +" strategy, China should boost the E-commerce development (e.g., the Internet), and expedite the transformation and upgrading of China's residents' consumption structure based on information and communication technologies and policies for promotion of residents' income growth, so as to facilitate the high-quality economic development in China. Finally, the construction of network infrastructure, especially that in Western China, should be strengthened. The improvement of Internet infrastructure underpins the role of Internet development in contributing to the upgrading of consumption structure. Compared with that in Eastern China and Central China, the Internet infrastructure in Western China is relatively backward, and the low income leads to a low Internet penetration rate in most regions. Therefore, the construction of network infrastructure in Western China should be strengthened, so as to drive the upgrading of residents' consumption structure.

\section{Acknowledgements}

This study is supported by the Major Research Project (2017) of Education Department of Guangdong Province for Research on Development of Cross-border E-commerce of SMEs in Guangdong Province in the Era of "Big Data" (2017 WTSCX 135); Featured Key Discipline E-commerce in Guangdong Province (2016) of Education Department of Guangdong Province.

\section{References}

1. Friedman, M. A Theory of the Consumption Function[M]. Princeton University Press. (1957)
2. Duesenberry J S. Income, Saving, and A Theory of Consumer Behavior[M]. Oxford University Press. (1967)

3. Keynes J M. General Theory of Employment, Interest and Money[M]. The American Economics Review, 26 (3): 490-493 (1936)

4. Yin SJ. Consumer Economics [M]. Beijing: Higher Education Press. (2007)

5. Mao ZG, Yang LJ. Supply-side Reform and the Residents " Consumption Structure Upgrade under the Economic Globalization Background [J]. Finance \& Economics, 1:72-82 (2017)

6. Xiang YB. Internet Development and Upgrading of Residents' Consumption Structure [J]. Journal of Zhongnan University of Economics and Law, 4:51-60 (2018)

7. Wang X. Research on the Effect and Mechanism of "Internet+" in Promoting Consumption Upgrading in China [J]. Collected Essays on Finance and Economics, 12: 94-102 (2016)

8. Du DQ. A Research on the Dynamic Mechanism of Internet boosts consumption upgrade [J]. Economist, 3:48-54. (2017)

9. Li XY, Li TP, Zou WJ. Has the Internet Promoted the Upgrading of Household Consumption? - Research Based on Micro Survey Data in China [J]. Journal of China University of Geosciences (Social Sciences Edition), 4:145-160 (2019)

10. $\mathrm{He} \mathrm{D}, \mathrm{Gu} \mathrm{J}$. Impact of the Internet on Rural Residents' Consumption Level and Structure-PSM An Empirical Study based on PSM and CFPS Data [J]. Rural Economy, 10:51-57 (2018)

11. Cheng MW, Zhang JP. Internet development and consumption gap between urban and rural residents in the new era of China [J]. The Journal of Quantitative \& Technical Economics, 2019(7):22-41.

12. Choi C, Yi M H. The Effect of the Internet on Economic Growth: Evidence from Cross-country Panel Data[J]. Economics Letters, 105(1): $39-$ 41 (2009)

13. Hu B. An Empirical Study on the Spillover Effect of China's Industrial Innovation under the Internet Economy [J]. On Economic Problems, 9:93-96+102 (2018)

14. Salahuddin M, Gow J. The Effects of Internet Usage, Financial Development and Trade Openness on Economic Growth in South Africa: A Time Series Analysis[J]. Telematics and Informatics, 33(4): 1141-1154. (2016)

15. Liu ZJ, Chen WJ. An Empirical Study on the Relationship between Internet Development Level and Economic Growth in China [J]. Economic Geography, 8:108-113+154 (2017)

16. Clarke G R, Scott J W. Has the Internet Increased 
Trade? Developed and Developing Country Evidence [J]. Economic Inquiry, 44(3) :465-484 (2006)

17. Bojnec S, Ferto I. Impact of the Internet on Manufacturing Trade[J]. Journal of Computer Information Systems, 50 (50):124-132 (2009)

18. Yang KJ, Chu TW. Internet Development, Transportation and Import: Spatial Econometric Analysis Based on Panel Data of China's 30 Provinces [J]. On Economic Problems, 6:95-100 (2016)

19. Pan JD, Xiao W. Study on Effects of Internet Development on China's Export [J]. Journal of International Trade, 12: 16-26 (2018)

20. Baltagi B, Egger P, Pfaffermayr M. A Generalized Spatial Panel Data Model with Random Effects[R]. Syracuse University, Working Paper. (2007)

21. Lesage J P, Pace R K. Introduction to Spatial Econometrics [M]. Taylor \& Francis. (2009)

22. Liu YF, Zhou YJ, Yang ZY. Housing Wealth Value and Household Consumption Structure Upgrade [J]. Journal of Hebei University of Economics and Trade, 4:17-29 (2018)
23. Wang W, Liu ZG, Gong FF. Impact of High Housing Prices on Upgrading of Consumption Structure: An Empirical Study Based on 35 Large and Medium-sized Cities [J]. Academic Research, 8: 87-96 (2017)

24. Pierre-Olivier Gourinchas; Jonathan A. Parker. Consumption over the Life Cycle[J]. Econometrica, 70(1): 47-89 (2002)

25. Ma BJ. Optimization of Consumption Structure: A Standard for Measuring the Optimization of Industrial Structure[J]. Consumer Economy, 6: 18-21 (2003)

26. Sun PY, Zhang JJ, Jiang XY. E-Commerce, Searching Cost and Consumer Price Change: Evidence from the Micro Retailing Market [J]. Economic Research Journal, 7:139-154 (2017)

27. Yang XK, Zhang YS. Emerging Classical Economics and Inframarginal Analysis [M] Beijing: Social Sciences Academic Press. (2003)

28. Liu H, Zhang JP. Research on the Effects of the Internet on the Consumption Structure of Rural Residents and Regional Difference In China [J]. Finance \& Economics, 4:80-88(2016) 